\title{
DHT deficiency perturbs the integrity of the rat seminiferous epithelium by disrupting tight and adherens junctions
}

\author{
Agnieszka Kolasa, Mariola Marchlewicz, Lidia Wenda-Różewicka, Barbara Wiszniewska \\ Department of Histology and Embryology, Pomeranian Medical University, Szczecin, Poland
}

\begin{abstract}
In rats with a DHT deficiency induced by finasteride, morphological changes in the seminiferous epithelium were observed. The structural alterations were manifested by the premature germ cells sloughing into the lumen of seminiferous tubules. The etiology of this disorder could be connected with intercellular junctions disintegration. We showed in the immunohistochemical study the changes in expression of some proteins building tight and adherens junctions. The depression of $\mathrm{N}$-cadherin, $\beta$-catenin and occludin immunoexpressions could be the reason for the release of immature germ cells from the seminiferous epithelium. However, the observed increase of the immunohistochemical reaction intensity of vinculin, one of the cadherin/catenin complex regulators, could be insufficient to maintain the proper function of adherens junctions. The hormonal imbalance appears to influence the pattern of expression of junctional proteins in the seminiferous epithelium. It could lead to untimely germ cells sloughing, and ultimately could impair fertility. (Folia Histochemica et Cytobiologica 2011, Vol. 49, No. 1, 62-71)
\end{abstract}

Key words: DHT-deficiency, intercellular junctions, testis, rat

\section{Introduction}

Spermatogenesis is defined as a process whereby germ cells divide, and differentiate into maturing spermatozoa in the company of Sertoli cells [1]. In the epithelium, Sertoli cells support nutrition and proper hormones concentration for germ cell development. Between the lateral processes of neighboring Sertoli cells, tight junctions (TJs) exist that divide the seminiferous epithelium into a basal compartment containing diploid (2n) spermatogonia, preleptotene/leptotene spermatocytes and an adluminal compartment containing more mature, haploid (1n) spermatocytes and spermatids [2]. TJs are constituted by several TJ-integral membrane proteins such as occludin, claudin and junctional adhesion molecules (JAMs). The Sertoli-Sertoli cell TJs constitute an important ele-

Correspondence address: A. Kolasa, Department of Histology and Embryology, Pomeranian Medical University,

Powstancow Wlkp. Str. 72, 70-111 Szczecin, Poland;

tel./fax: (+ 48 91) 46616 77;

e-mail: ak1712@sci.pam.szczecin.pl ment of the blood-testis barrier (BTB). However, within the BTB complex of various intercellular adherens junctions (AJs) are also present [3-5].

The physical division of the SE into basal and adluminal compartments is based on the localization of the BTB; therefore the intercellular junctions between adjacent cells are classified according to their localization and the type of attachment cytoskeleton molecules [6]. In both basal and adluminal compartments of the seminiferous epithelium, adherens junctions (AJs) exist. Adherens junctions are actin-based junctions (ectoplasmic specialization, tubulobulbar complex) or intermediate filaments-based junctions (desmosome-like junction) [6]. The ectoplasmic specializations (ESs) are the most studied actin-based testisspecific type of AJs, and are regarded as very important for proper spermatogenesis. The basal ESs support the thigh junctions of the BTB structure between adjacent Sertoli cells [7], whereas the apical ESs between Sertoli cell and spermatids (round/elongating/elongated) participate in intercellular adhesion and movement of germ cells through the SE, as well as contributing to the orientation, positioning and correct shape of 
the forming spermatozoa head [8]. The complex of various molecules among the integral membrane junctional components of ESs is present [9-13]. The best recognized is the cadherin/catenin complex that is found in both apical and basal ESs [6]. In the basal ESs, $\beta$-catenin co-localizes with $\mathrm{N}$-cadherin [14] and at the ESs site, vinculin, actin-binding protein is located. Vinculin, as a putative substrate for protein kinase, is involved in junction assembly, stabilization and regulation $[6,15]$; therefore vinculin is mentioned as a crucial regulator of the cadherin/ /catenin complex.

TJs and AJs strictly interact together to form a very firm, tight and non-leaking barrier that provides a specific microenvironment for developing germ cells by sequestering proteins from the interstitial systemic circulation before they enter the seminiferous epithelium $[6,16,17]$. The barrier participates in isolation of the post-meiotic germ cells from the self-immune system and avoids autoimmune response development [18]. Consequently, the testis is known as an immunologically privileged organ [19]. The main function of intercellular junctions between Sertoli and germ cells is giving the immature germ cells (preleptotene and leptotene spermatocytes) permission to migrate progressively through the height of the SE, from the basal to the adluminal compartment, traversing the BTB $[6,20]$. The structure of intercellular junctions, participating in the passage of germ cells throughout the epithelium, is changing during the SE cycle and depends on hormonal balance [18, 20-22].

The male gonad is an androgen-dependent organ. In androgen target tissues, testosterone $(\mathrm{T})$ can be irreversibly reduced into more active dihydrotestosterone (DHT). The process is catalyzed by $5 \alpha$-reductase ( $5 \alpha$-red) that exists in two isoforms: $5 \alpha$-reductase type $1(5 \alpha$-red 1$)$ and type $2(5 \alpha$-red2) [23]. Some authors have estimated by northern blot analysis that immature rat testes have higher levels of $5 \alpha$-red 1 then those of the adult [24]. The expression of $5 \alpha$-red 2 in the male gonad was detectable at any age [25]. Other studies have strongly suggested that the major isoenzyme present in testicular tissues is $5 \alpha$-reductase type 2 [26-29]. Therefore, in our study (carried out with mature rats), we inhibited the $5 \alpha$-red 2 activity by finasteride, which is used in basic and clinical studies as the one of the best inhibitors of the enzyme [23,30]. In our previous studies, we had found that 28 and 56 day DHT-deficiency altered the androgen receptor (AR) [31], estrogen $\alpha$ and $\beta$ receptors $(\mathrm{ER} \alpha, \mathrm{ER} \beta)$ in epididymis [32], antioxidant enzymes (GPX5, E-SOD, $\mathrm{Cu} / \mathrm{Zn} \mathrm{SOD}$ ) [33] and inducible nitric oxide synthase (iNOS) [34] expression patterns. The changes in the morphology of testes were noticed after a long period (56 days) of androgen imbalance [35].
Because of that, the aim of this current study was to examine the immunolocalization of AJ components: $\beta$-catenin, $\mathrm{N}$-cadherin, their regulator — vinculin and TJ occludin in the seminiferous epithelium of rat testis during DHT deficiency.

\section{Materials and methods}

\section{Animals}

Sexually mature male Wistar rats (three months old) were housed singly, kept on a 12 hours of light, 12 hours of dark cycle and given food and water $a d$ libitum. The study was approved by the Local Ethics Committee for Scientific Experiments on Animals in Szczecin (Poland). The animals were randomly divided into a control group (ten animals) and two experimental (finasteride-treated rats) groups (five animals per group). Finasteride (Proscar ${ }^{\circledR}$, MSD Sweden) was administered per os at a dose of $5 \mathrm{mg} / \mathrm{kg}$ b.w./day for 28 days - two cycles of the seminiferous epithelium (the first experimental group - Fin 28) and for 56 days - the total time of spermatogenesis (the other experimental group - Fin56). After the experiment, the rats were anesthetized with thiopental (Biochemie $\mathrm{GmbH}$, Austria), administered in a dose of $120 \mathrm{mg} / \mathrm{kg}$ b.w. intraperitoneally. The testes were fixed in $4 \%$ buffered formalin and processed for embedding in paraffin for immunohistochemistry and histological staining.

\section{PAS method}

The paraffin-embedded tissue samples were stained with PAS (Periodic Schiff Acid) technique according to McManus described by Totty [36] assess the seminiferous tubules morphology and to visualize the acrosome that helps establish the stages of seminiferous cycles.

\section{Immunohistochemistry (IHC)}

The paraffin-embedded sections $(3-5 \mu \mathrm{m})$ of rat testes were immunostained for visualization of chosen components of intercellular junctions. The IHC was performed using specific primary antibodies: for adherens junction: anti-vinculin, anti-N-cadherin, anti-beta-catenin; for tight junction: anti-occludin (Table 1). The deparaffinized sections were microwave irradiated in citrate buffer ( $\mathrm{pH}$ 6.0) to heat induced epitope retrieval. After slow cooling to room temperature, slides were washed in PBS twice for five minutes each and then incubated for 30 minutes with primary antibodies. Then, sections were stained with 
Table 1. Antibody specifications

\begin{tabular}{|l|c|c|c|}
\hline Antibody/clone & Antibody & Dilution & Producer/cat. no. \\
\hline Vinculin/h-Vin1 & Mouse monoclonal & $1: 200$ & Sigma Chemical Corporation/V-9131 \\
\hline N-cadherin/CDH2 & Rabbit polyclonal & $1: 100$ & Santa Cruz Biotechnology/sc-7939 \\
\hline Beta-catenin/CATNB & Rabbit polyclonal & $1: 100$ & Santa Cruz Biotechnology/sc-7199 \\
\hline Occludin/H-279 & Rabbit polyclonal & $1: 100$ & Santa Cruz Biotechnology/sc-5562 \\
\hline
\end{tabular}

an avidin-biotin-peroxidase system with diaminobenzidine as the chromogen (DAKO (HRP; rabbit/mouse/goat (DAB+) code no. K0679; DakoCytomation) in conformity with the staining procedure instruction included in Dako LSAB + System-HRP. Sections were washed in distillated water and counterstained with hematoxylin. Our investigation made comparisons between stages I or II, VII or VIII and $\mathrm{X}$-XII of the SE cycle of control and two experimental groups were made. For negative controls, specimens were processed in the absence of a primary antibody. Positive staining was defined microscopically by visual identification of brown pigmentation.

\section{Results}

\section{PAS method}

After 28 days of finasteride treatment, the seminiferous tubules (Figure 1B) showed normal morphology, similar to that observed in the control rats (Figure 1A). There were all generations of germ cells, characteristic of the appropriate stage of the seminiferous epithelium cycle (Figure 1A, B). After 56 days of finasteride treatment, the cross-sections of the seminiferous tubules showed the presence of sloughed immature germ cells in the lumen (Figure 1C), mainly spermatids in different steps of development (Figure 2A-D), rarely pachytene spermatocytes (Figure 2B). Empty areas within the SE were noticed (Figures $1 \mathrm{C}, 2 \mathrm{~A}-\mathrm{C})$.

\section{Immunohistochemistry}

In all studied groups (control, Fin28, Fin56) the junctional proteins, within the cells of the SE, were expressed with different intensity (Figures 3-6).

\section{$N$-cadherin}

The most intensive $\mathrm{N}$-cadherin expression was visible in the basal part (white asterisks) of the SE, (spermatogonia A1, intermediate spermatogonia, pachytene spermatocytes) in stages II (Figure 3A) and VIII (Figure 3D) of the SE cycle in the testes of control rats. The immunoexpression of $\mathrm{N}$-cadherin was quite low in round spermatids steps $2^{\text {nd }}$ and $8^{\text {th }}$ (Figures 3A, D; black arrows). Much more intensive immunoreaction was noticeable in the steps $16^{\text {th }}$ and $19^{\text {th }}$ elongated spermatids (Figures 3A, D; blue arrows). Intensive $\mathrm{N}$-cadherin expression was visible mainly between zygotene spermatocytes (ZS) (white arrows) and steps $12^{\text {th }}-13^{\text {th }}$ elongating spermatids (blue arrows) in stage XII of the SE cycle of control rats (Figure 3G). The intensity of IHC reaction was lower in areas of epithelium in which PS were present (Figure 3G; black arrow). The product of IHC-reaction was weakly visible in both finasteride-treated groups (Figures 3B, C, E, F, H, I) in comparison to the control group. It was observed generally in the cells near the basal membrane (white asterisk) and in the elongating spermatids of the $16^{\text {th }}$ (Figures 3B, C; blue arrows), $19^{\text {th }}$ (Figures 3E, F; blue arrows) and $10^{\text {th }}-12^{\text {th }}$ (Figures $3 \mathrm{H}$, I; blue arrows) steps. Moreover, the sloughed immature germ cells into the seminiferous tubules lumen of 56Fin rats were also immunopositive (Figures 3C, F; green asterisks).

\section{$\beta$-catenin}

The $\beta$-catenin expression in the testes of the control rats, in all examined stages of the SE (Figure 4A, D, G), was evident at the basal part of epithelium (Figure 4A, D, G; white asterisks). Brown color, indicating the presence of $\beta$-catenin, encircled round spermatids at the II (Figure 4A; black arrows) and VIII (Figure 4D; black arrows) stages of the SE cycle. The elongating spermatids of $11^{\text {th }}$ $-12^{\text {th }}$ steps (Figure 4G; blue arrows) and elongated spermatids (Figures 4A, D; blue arrows) showed a very weak positive reaction.

The pattern of $\beta$-catenin immunoexpression within the SE of Fin28 (Figures 4B, E, H) and Fin56 (Figures 4C, F, I) rats was similar to the control, but intensity of $\beta$-catenin immunoexpression was significantly decreased. However, the step $19^{\text {th }}$ spermatids (just prior to spermiation) of the Fin56 group appear immunopositive (Figure 4F; blue arrows). 

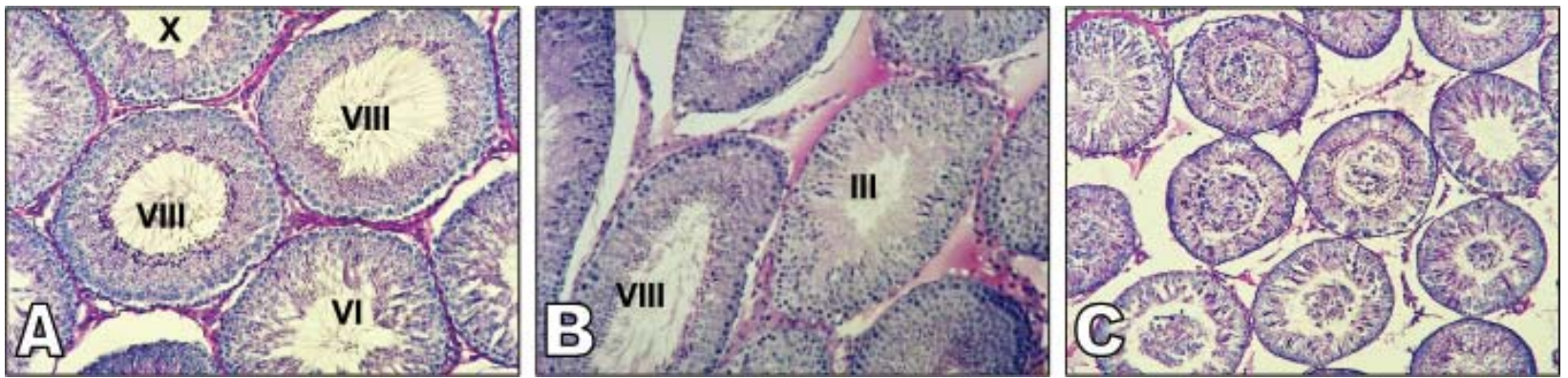

Figure 1. Cross-sections of a control rat testis. A. Stages VI, VIII and X of the seminiferous epithelium. Within the tubules, all germ cells generations appropriate for particular stages of the seminiferous epithelium cycle are present; B. Testis of a Fin28 rat. Unchanged structure of the seminiferous tubules. Stages III, VIII of the seminiferous epithelium cycle; C. The prematurely sloughed germinal cells visible in the lumen of seminiferous tubules of a Fin56 rat. Objectives magnification: $\mathrm{A}, \mathrm{B} \times 20 ; \mathrm{C} \times 10$
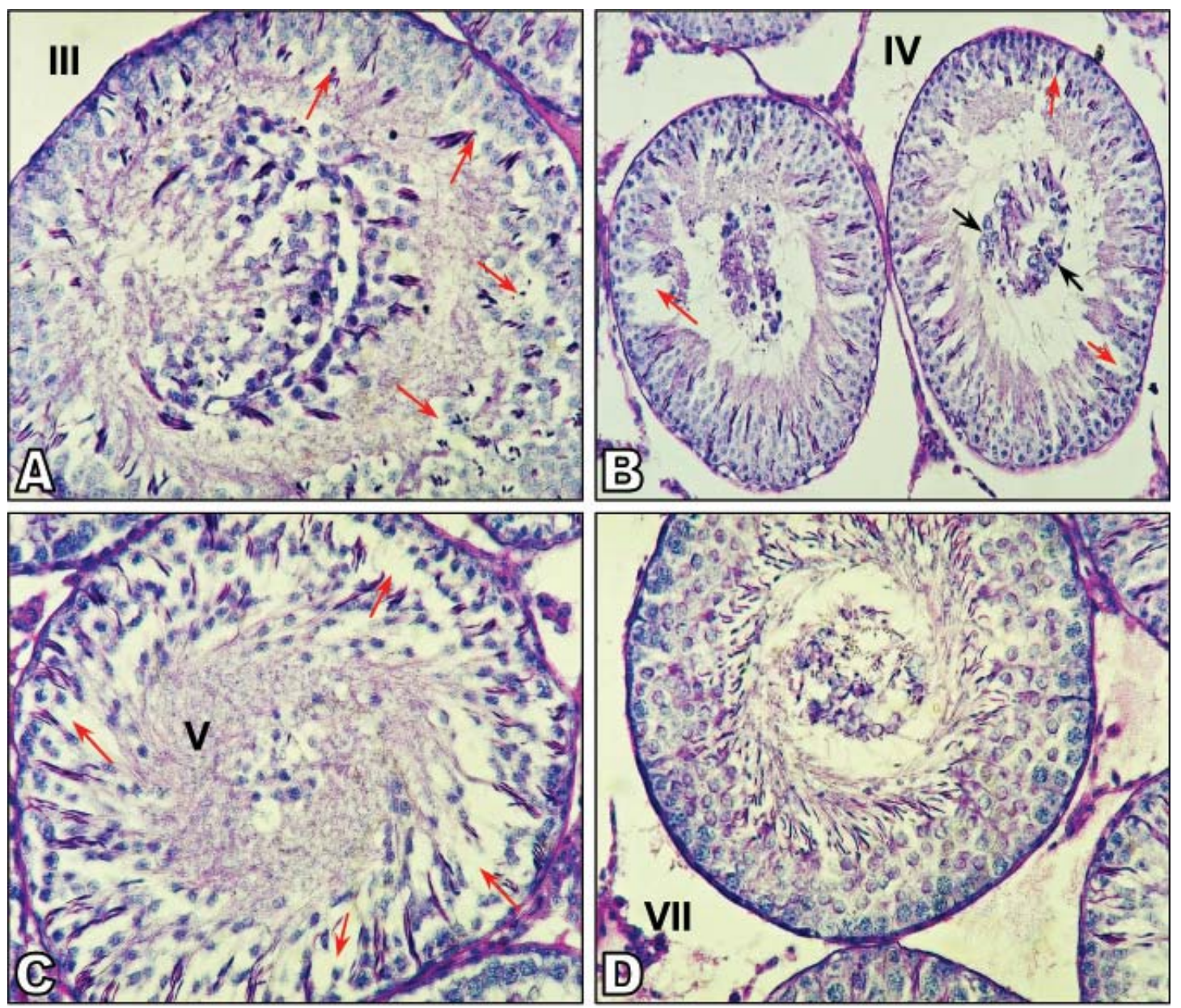

Figure 2. Cross-sections of the seminiferous tubules of a rat which has received finasteride for 56 days. A. Stage III of the SE cycle. In the lumen of tubules sloughed spermatids step $3^{\text {rd }}$ (red arrows) are visible; B. Stage IV of the SE cycle. In the lumen of tubules, sloughed step $4^{\text {th }}$ spermatids (left tubule) and pachytene spermatocytes (black arrows), step $17^{\text {th }}$ spermatids (right tubule) are present. Within the SE empty spaces (red arrows) are visible; C. Stage V of the SE cycle with empty spaces (red arrows) and sloughed into the lumen step $5^{\text {th }}$ spermatids; D. Stage VII of the SE cycle with sloughed step $7^{\text {th }}$ spermatids in the lumen of tubules. Objectives magnification: $\mathrm{B} \times 20 ; \mathrm{A}$. C, D $\times 40$ 
Control
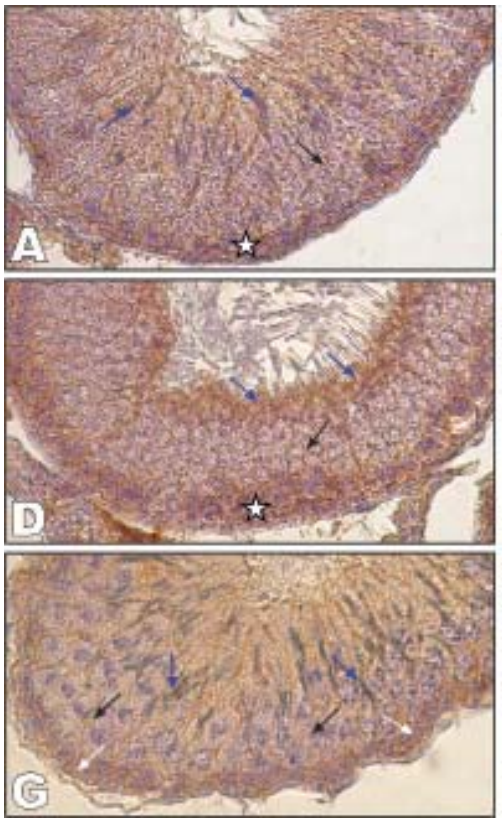

Fin 28
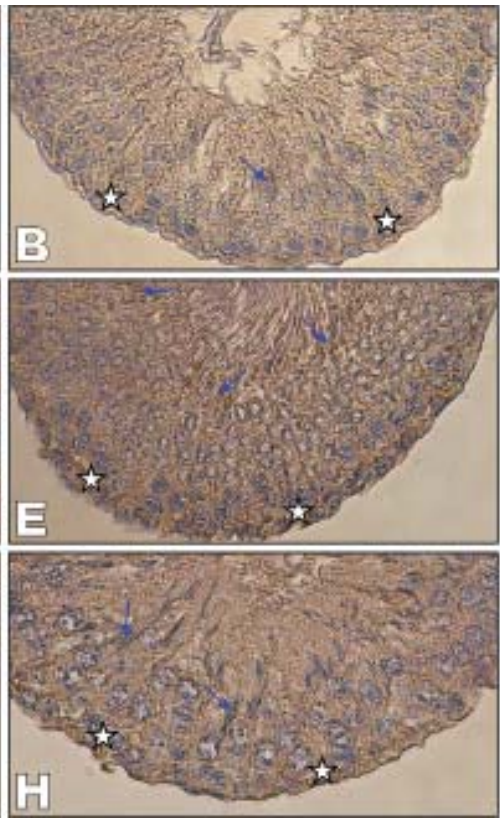

Fin 56

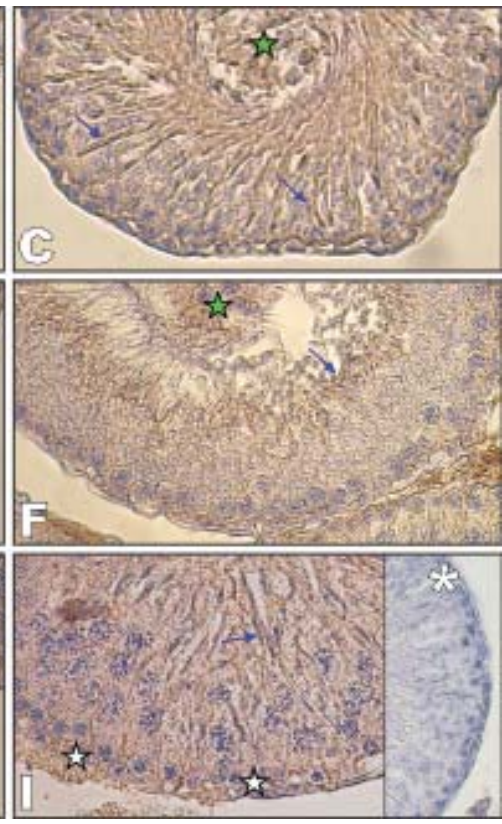

I-II

VII-VIII

X-XII

Figure 3. The immunoexpression of N-cadherin in the testes of control (A, D, G), Fin28 (B, E, H) and Fin56 (C, F, I) rats. The seminiferous tubules in stages I or II (A, B, C), VII or VIII (D, E, F) and X-XII (G, H, I) of the SE cycles. No immunostaining in seminiferous epithelium in negative control of IHC reaction with omitting of primary antibody (I - insert *). Objective magnification: A-I $\times 40$. The arrows and asterisks legends: blue arrows - steps $10^{\text {th }}-12^{\text {th }}$ elongating SD $(\mathbf{H}, \mathbf{I}), 16^{\text {th }}(\mathbf{A}-\mathbf{C})$ and $19^{\text {th }}(\mathbf{D}-\mathbf{F})$ elongated SD; black arrows - steps $2^{\text {nd }}(\mathbf{A}), 8^{\text {th }}(\mathbf{D})$ round SD and $12^{\text {th }}(\mathbf{G})$ elongating SD; white arrows - ZS $(\mathbf{G})$; white asterisks - basal part of seminiferous epithelium (A-F, H, I); green asterisk — sloughed immature germ cells $(\mathbf{C}, \mathbf{F})$

Control
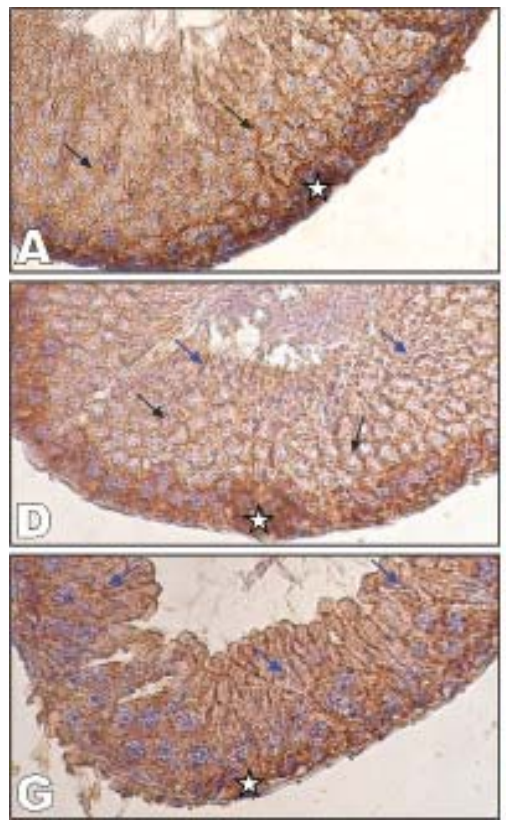

Fin 28
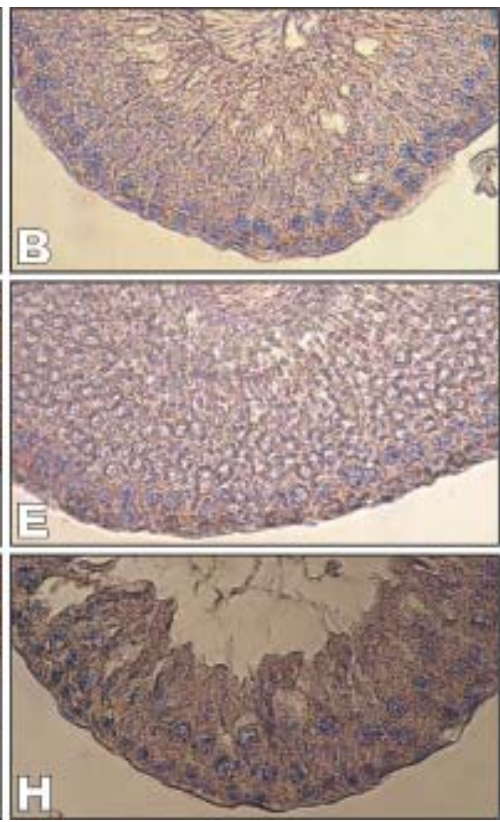

Fin 56

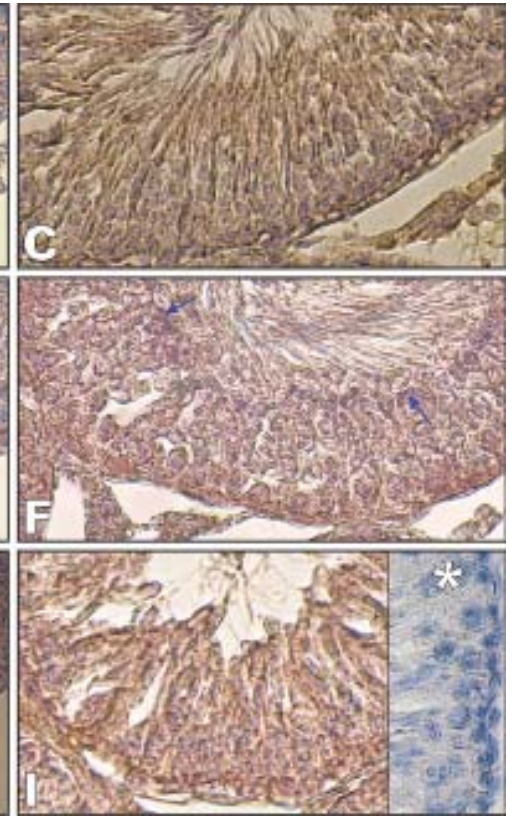

I-II

VII-VIII

X-XII

Figure 4. The immunoexpression of $\beta$-catenin in the testes of control $(\mathbf{A}, \mathbf{D}, \mathbf{G})$, Fin28 (B, E, H) and Fin56 (C, F, I) rats. The seminiferous tubules in stages I or II $(\mathbf{A}, \mathbf{B}, \mathbf{C})$, VII or VIII $(\mathbf{D}, \mathbf{E}, \mathbf{F})$ and X-XII $(\mathbf{G}, \mathbf{H}, \mathbf{I})$ of the SE cycles. No immunostaining in seminiferous epithelium in negative control of IHC reaction with omitting of primary antibody $\left(\mathrm{I}-\right.$ insert $\left.^{*}\right)$. Objective magnification: A-I $\times 40$. The arrows and asterisks legends: blue arrows - steps $10^{\text {th }}-12^{\text {th }}$ (G) elongating SD, $16^{\text {th }}(\mathbf{A})$ and $19^{\text {th }}(\mathbf{D}, \mathbf{F})$ elongated SD; black arrows - steps $2^{\text {nd }}(\mathbf{A}), 8^{\text {th }}(\mathbf{D})$ round SD; white asterisks - basal part of SE (A, D, G) 


\section{Vinculin}

The immunoexpression of vinculin in the testes of control rats was weakly marked (Figures 5A, D, G). Brown pigmentation, indicating the positive statement of immunoreactions, has the strandline pattern extending throughout the SE height. The IHC reaction was visible in the Sertoli - spermatids attachment site in stages I-II (Figure 5A; red arrows) and X-XII (Figure 5G; red arrows) of the SE cycle.

The vinculin immunoexpression increased in finasteride-treated rats' testes (Figures 5B, C, E, F, H, I). Therefore, the radial motif was better evident in the seminiferous tubules cross-sections, particularly in the Fin56 group (Figures 5C, F, I; red arrows), mainly in stages VII-VIII (Figure 5F) of the SE cycle. Additionally, the basal compartment of the SE (spermatogonia, preleptotene spermatocytes) also shows a strong positive product of IHC reaction (Figures 5B, C, E, F, H, I; white asterisks).

\section{Occludin}

The immunoexpression of occludin was prominent in the basal part of control rats SE (Figures 6A, D, $\mathrm{G}$; white asterisks). The brown pigmentation, which confirms the positive score of immunoreaction, was located in the area enveloping the primary spermatocytes (preLS, ZS, PS). Both round (Figures 6A, D; black arrows) and elongating/elongated spermatids (Figures 6A, D, G; blue arrows) demonstrate rather low occludin expression.

The level of occludin declined in the testes of rats in the finasteride-treated groups (Figures 6B, C, E, $\mathrm{F}, \mathrm{H}, \mathrm{I}$ ) independently of SE cycle stages, much more within long-term DHT deficiency group (Figures 6C, F, I). In the Fin 28 group, the positive score of immunoreactions was visible only in a few primary spermatocytes (Figures 6E, H; red arrows).

\section{Discussion}

After the first meiotic division of primary spermatocytes, the haploid cells are produced. Consequently, secondary spermatocytes, differentiating spermatids and spermatozoa could be recognized by the immune system as a foreign body. It means that, at the same time, germ cells have to divide and traverse the seminiferous epithelium according to the periodic changes of junctions disassembly and assembly without altering the immunological barrier function [37]. Therefore, the integrity of the blood-testis barrier is extremely essential for separation of the haploid reproductive cells from the immunocompetent cells, and the proper function of the other junctions is required for appropriate arrangement of germ cells within the lateral processes of Sertoli cells and their passage through the epithelium. The germ cells movement across the $\mathrm{SE}$ is associated with remodeling of adherens and thigh junctions $[6,38]$, and in the rat takes place at late stage VIII through early stage IX of the seminiferous epithelium cycle $[6,20]$.

Very early investigations showed that round spermatids (pre-step $8^{\text {th }}$ spermatids in rat), and less-differentiated germ cells types are loosely attached to Sertoli cells by desmosome-like junctions [22, 39-42]. It was also shown that at stage VIII of the SE cycle in rats, the step $8^{\text {th }}$ spermatids are attached to the Sertoli cell by unique, highly specialized, actin-based cytoskeletal structures - ectoplasmic specializations $[41,42]$. Elongating spermatids (post-step $8^{\text {th }}$ spermatids in the rat) are associated with Sertoli cells by the extremely tight ectoplasmic specialization [21, 22]. An in vitro study indicated that the cytoskeleton of junction-related structures of Sertoli cells that join prestep $8^{\text {th }}$ spermatids are different than those observed between the Sertoli cell and post-step $8^{\text {th }}$ spermatids [43]. The ectoplasmic specializations also exert an important role in remodeling BTB [38]. At stage VIII of the rat's SE cycle, the active laminin fragments of apical ESs induce blood-testis barrier disruption directly, by reducing the steady-state levels of integral membrane proteins at the BTB [38].

Similarly, cytokines (TNF $\alpha$, TGF- $\beta 2$, TGF- $\beta 3$ ) and testosterone induce protein endocytosis at BTB. The factors mentioned above 'de-stabilize' the BTB, facilitating the transit of preleptotene spermatocytes. Testosterone promotes BTB integrity, but also can enhance de novo synthesis of TJ-proteins, as well as promote transcytosis of endocytosed proteins from 'old' disrupted TJ-fibrils of above the primary preleptotene spermatocytes to 'new' assembly TJ-fibrils below the pachytene spermatocytes [38].

The results of our study indicate that dihydrotestosterone, a more active metabolite of testosterone, could play an important role in the physiology of junctions complex of BTB. Although we did not notice an alteration in the morphology of SE of rats with 28-day-long DHT deficiency, the changes of immunoexpression of occludin and $\mathrm{N}$-cadherin/ $\beta$-catenin/ vinculin were perceptible and similar to those in Fin56 rats. Moreover, a long period of finasteride treatment caused changes in the morphology of the SE. This concords with the observations of O'Donnell et al. [44-46] who proved suppressed spermatogenesis mainly at the spermatids conversion from step $7^{\text {th }}$ to step $8^{\text {th }}$ during deficit of DHT. In our study, we also detected that finasteride-induced DHT deficiency lasting the period of one spermatogenesis (56 days) resulted in sloughing immature germ cells in $7^{\text {th }}$ step, but also an earlier $\left(3^{\text {rd }}-5^{\text {th }}\right)$ and later $\left(17^{\text {th }}\right)$ steps of spermatids differentiation. Occasionally, we noticed 
Control
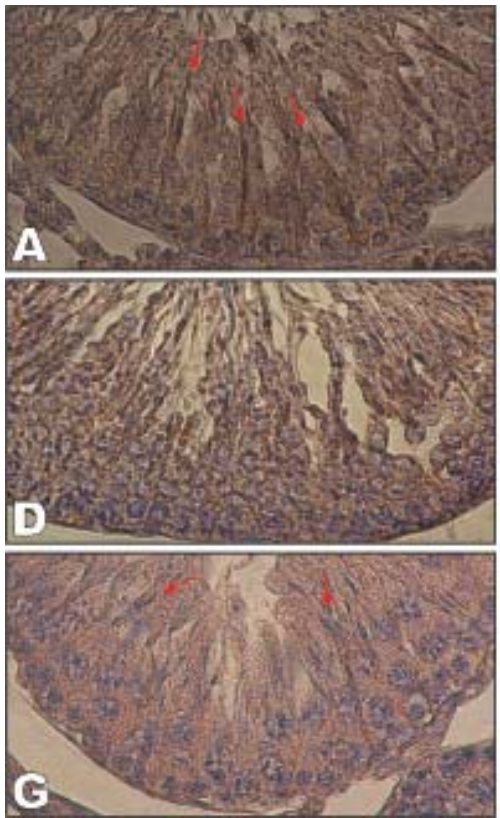

Fin 28

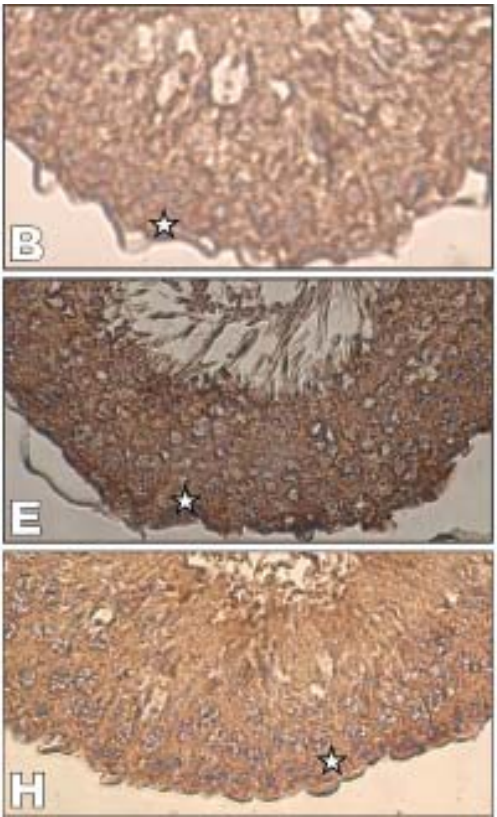

Fin 56

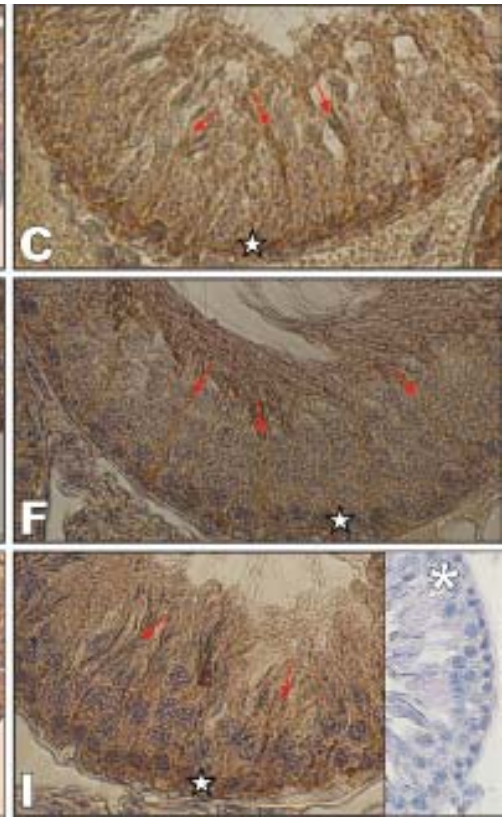

I-II

VII-VIII

$\mathrm{X}-\mathrm{XII}$

Figure 5. The immunoexpression of vinculin in the testes of control (A, D, G), Fin28 (B, E, H) and Fin56 (C, F, I) rats. The seminiferous tubules in stages I or II (A, B, C), VII or VIII (D, E, F) and X-XII (G, H, I) of the SE cycles. No immunostaining in seminiferous epithelium in negative control of IHC reaction with omitting of primary antibody $(\mathrm{I}-$ insert *). Objective magnification: A-I $\times 40$. The arrows and asterisks legends: red arrows - radial motif of vinculin immunoexpression (A, C, F, G, I); white asterisks — basal compartment of SE with SG and pre-meiotic spermatocytes $(\mathbf{B}, \mathbf{C}, \mathbf{E}, \mathbf{F}, \mathbf{H}, \mathbf{I})$

Control
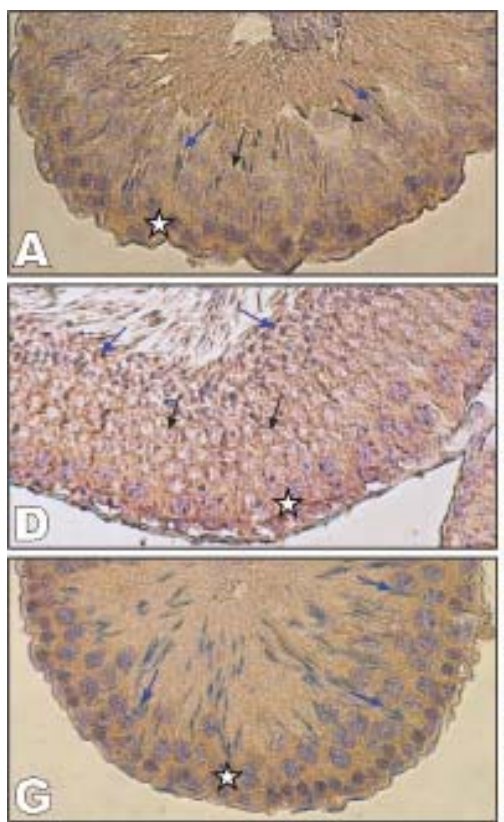

Fin 28
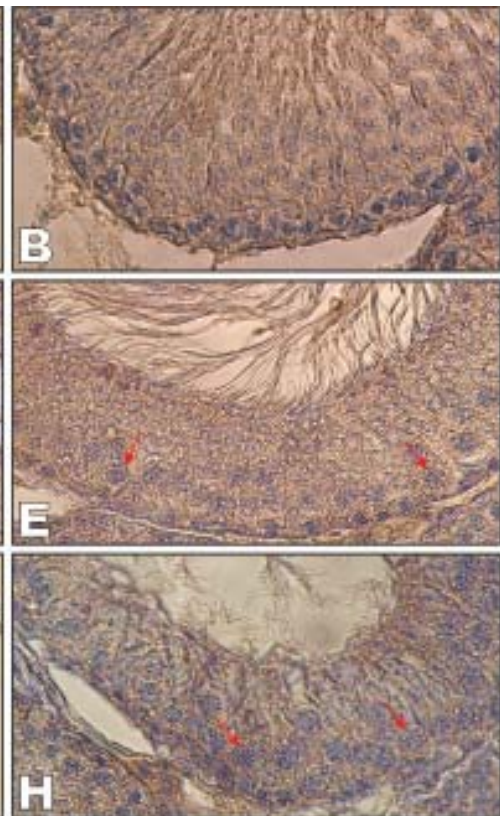

Fin 56

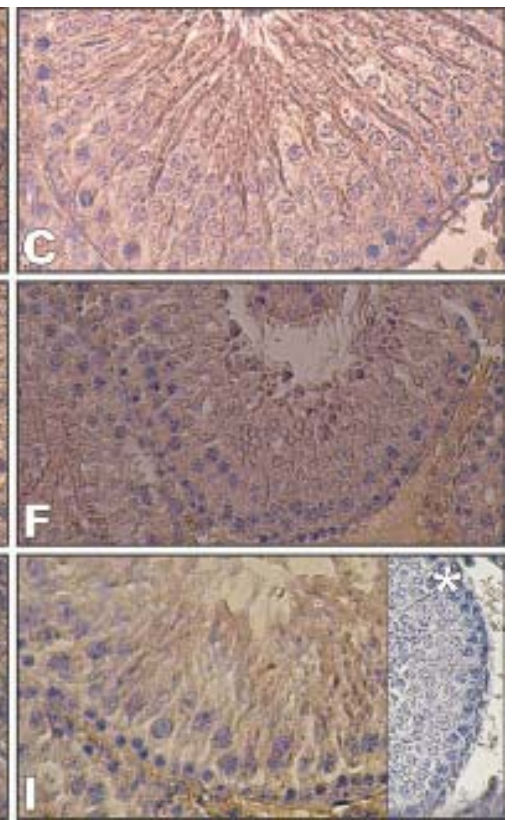

I-II

VII-VIII

X-XII

Figure 6. The immunoexpression of occludin in the testes of control $(\mathbf{A}, \mathbf{D}, \mathbf{G})$, Fin28 (B, E, H) and Fin56 (C, F, I) rats. The seminiferous tubules in stages I or II (A, B, C), VII or VIII $(\mathbf{D}, \mathbf{E}, \mathbf{F})$ and X-XII $(\mathbf{G}, \mathbf{H}, \mathbf{I})$ of the SE cycles. No immunostaining in seminiferous epithelium in negative control of IHC reaction with omitting of primary antibody $\left(\mathrm{I}-\right.$ insert *). Objective magnification: A-I $\times 40$. The arrows and asterisks legends: black arrows - steps $2^{\text {nd }}(\mathbf{A}), 8^{\text {th }}$ (D) round SD; red arrows - primary spermatocytes; blue arrows — steps $10^{\text {th }}-12^{\text {th }}(\mathbf{G})$ elongating SD, $16^{\text {th }}(\mathbf{A})$ and $19^{\text {th }}$ (D) elongated SD; white asterisks — basal part of SE (A, D, G) 
the presence of pachytene spermatocytes in the lumen of tubules. A proper level of DHT is important, because it is involved in maintaining the spermatogenesis during very low androgen concentrations (10$-20 \%$ of the norm) in gonads [47]. The ultrastructural study by O'Donnell et al. [48] showed that ectoplasmic specializations are normal in the SE of adult rats with testosterone suppressed by low-dose T and E2 treatment, and the detachment of the premature step $8^{\text {th }}$ spermatids from Sertoli cell [49] was caused probably by defects in adhesion molecules such as epsin, actin and vinculin between round spermatids and Sertoli cells [48]. We observed an increase of vinculin immunoexpression that was much more visible in the $\mathrm{SE}$ of rats treated with finasteride for 56 days. However, the other proteins of adherens junctions studied by us display a somewhat contrary tendency. Because vinculin is considered as the regulator of the cadherin/catenin complex $[6,15]$, we hypothesised that during the decline in cadherin and catenin expression, the increase of vinculin could be one of the protective mechanisms for preserving as well as possible the function of the SE in hormonal imbalance condition. However, this hypothesis needs more detailed examination.

Lee et al. [50] suggested that interactions between Sertoli cells and germ cell are crucial for expression of $\beta$-catenin. So, the reduction of its immunoexpression in our study could be correlated with a decrease of the germ cell adhesive capacity.

The main function of ectoplasmic specializations is to facilitate germ cell movement, but additionally the ESs have an anchoring function to retain germ cells, particularly spermatids in the epithelium until spermiation [7, 16, 42]. Therefore, some hormonal disruption, like DHT deficiency, leads to change in the immunoexpression of structural (cadherin/catenin) and regulatory (vinculin) junctional proteins and finally affects the integrity of ESs and perturbs its functions mentioned above, as well as possibly influencing remodeling of the blood-testis barrier [38].

Our study also found changes in occludin immunoexpression. The occludin decline could be the next reason for the immature germ cell sloughing into the lumen of seminiferous tubules of finasteride-treated rats. Literature data confirming regulation of occludin expression by androgen is scarce. It has been documented that $\mathrm{TJ}$ dynamics in the testis is regulated by nitric oxide synthase (NOS) [51]. During testes maturation, the mRNA levels of iNOS and eNOS in both Sertoli and germ cells are changing. In the maturating Sertoli cells, the iNOS expression dramatically increased compared to eNOS and in germ cells the iNOS mRNA plunged, whereas the eNOS mRNA level rose during maturation. Taken together, these findings illustrate the different responses of NOS isoforms in Sertoli and germ cells during testes maturation, and suggest the important biological function of NO to maintain testis function [50].

Our previous experiment indicated that finasteride-induced DHT deficiency intensified expression of iNOS in most rat testicular cells [34]. It can be assumed that DHT deficiency, through the elevated NO production, causes the decline of occludin immunoexpression, and thereby germ cell sloughing. Moreover, the tight junctions secure the isolation of spermatozoa from the immune system, so the increase of BTB leaking could induce local inflammation in the male gonad. We observed that during finasteride-induced hormonal disturbance, the immunoexpression of IL-6, a cytokine considered as a pro-inflammatory factor, increased (data not shown). Therefore, the DHT deficiency could cause the local inflammatory process with IL6 participation and might negatively affect spermatogenesis in the testis.

In conclusion, our data indicates that finasterideinduced DHT deficiency changes the expression of junctional proteins involved in the building of tight and adherens junctions in the seminiferous epithelium of rats. Therefore, it can be expected that the structure and function of the blood-testis barrier can be regulated by DHT. Imbalance in androgens homeostasis can lead to untimely release of immature germ cells from the SE into seminiferous tubules lumen, and consequently can decrease the number of spermatozoa produced by the testis and thus decrease male fertility.

\section{Abbreviations}

AJ - adherens junction; $5 \alpha$-red $-5 \alpha$-reductase; $5 \alpha$-red $1-5 \alpha$ -reductase type $1 ; 5 \alpha$-red2 - $5 \alpha$-reductase type 2; AR - androgen receptor; $\mathrm{BTB}$ - blood-testis barrier; $\mathrm{Cu} / \mathrm{Zn} \mathrm{SOD} \mathrm{—} \mathrm{copper/}$ /zinc superoxide dismutase; DHT - dihydrotestosterone; E2 estradiol; E-SOD — extracellular superoxide dismutase; ER $\alpha$ estrogen receptor $\alpha$; ER $\beta$ - estrogen receptor $\beta$; ES- ectoplasmic specializations; GPX5 - epididymal specific glutathione peroxidase 5; IHC — immunohistochemistry; LC — Leydig cell; NO — nitric oxide; NOS — nitric oxide synthase; iNOS — inducible nitric oxide synthase; eNOS - endothelial nitric oxide synthase; PS - pachytene spermatocyte; preLS - preleptotene spermatocyte; SC — Sertoli cell; SD — spermatid; SE — seminiferous epithelium; SG — spermatogonium; $\mathrm{T}$ - testosterone; TJ — tight junction; ZO — zonula occludens; ZS — zygotene spermatocyte

\section{References}

1. Hermo L, Pelletier RM, Cyr DG, Smith CE. Surfing the wave, cycle, life history and genes/proteins expressed by testicular germ cells. Part 1: Background to spermatogenesis, spermatogonia and spermatocytes. Microsc Res Tech. 2010;73:243-278.

2. Yazama F. Continual maintenance of the blood-testis barrier during spermatogenesis: the intermediate compartment theory revisited. J Reprod Develop. 2009;54:299-305. 
3. de Kretser DM, Kerr JB. The cytology of the testis. In: Knobil E., Neill J, ed. The Physiology of Reproduction. New York: Raven Press; 1988:837-932.

4. Russell LD, Ettlin RA, Sinha-Hikim AP, Clegg EJ. Mammalian Spermatogenesis. In: Russell LD, Ettlin RA, SinhaHikim AP, Clegg EJ, ed. Histological and histopathological evaluation of the testis. Clearwater, FL: Cache River Press; 1990:1-40.

5. Byers SW, Jegou B, MacCalman C, Blaschuk OW. Sertoli cell adhesion molecules and the collective organization of the testis. In: Russell LD, Griswold MD, ed. The Sertoli Cell. Clearwater, FL: Cache River Press; 1993:461-476.

6. Cheng CY, Mruk DD. Cell junction dynamics in the testis: Sertoli-germ cell interactions and male contraceptive development. Physiol Rev. 2002;82:825-874.

7. Lee NPY, Cheng Y. Ectoplasmic specialization, a testis specific cell-cell actin-based adherens junction type: is this a potential target for male contraceptive development? Hum Reprod Update. 2004;10:349-369.

8. Mruk DD, Cheng CY. Sertoli-Sertoli and Sertoli-germ cell interactions and their significance in germ cell movement in the seminiferous epithelium during spermatogenesis. Endocr Rev. 2004;25:747-806.

9. Lee NPY, Mruk DD, Conway AM, Cheng Y. Zyxin, axin, and WASP are adaptors that link the cadherin/catenin protein complex to cytoskeleton at adherens junctions in the seminiferous epithelium of the rat testis. $J$ Androl. 2004;25: 200-215.

10. Liu WY, Mruk DD, Lee WM, Cheng Y. Adherens junction dynamics in the testis and spermatogenesis. J Androl. 2003;24:1-14.

11. Siu MKY, Mruk DD, Lee WM, Cheng CY. Adhering junction dynamics in the testis are regulated by an interplay of $\beta 1$-integrin and focal adhesion complex-associated protein. Endocrinology. 2003;144:2141-2163.

12. Siu MKY, Cheng CY. Interactions of proteases, protease inhibitors, and the $\beta 1$-integrin/laminin $\gamma 3$ protein complex in the regulation of ectoplasmic specialization dynamics in the rat testis. Biol Reprod. 2004;70:945-964.

13. Lau ASN, Mruk DD. Rab8B GTPase and junction dynamics in the testis. Endocrinology. 2003;144:1549-1563.

14. Lee NPY, Mruk DD, Lee WM, Cheng Y. Is the cadherin/ catenin complex a functional units of the cell-cell actin-based adherens junctions in the rat testis? Biol Reprod. 2003;68: 489-508.

15. Siu MKY, Cheng CY. Extracellular matrix: Recent advances on its role in junctional dynamic in the seminiferous epithelium during spermatogenesis. Biol Reprod. 2004; 71:375-391.

16. Vogl AM, Pfeiffer DC, Molholland D, Kimel G, Guttman $\mathrm{J}$. Unique and multifunctional adhesion junctions in the testis: ectoplasmic specialization. Arch Histol Cytol. 2000; 63:1-15.

17. Toyama Y, Meakawa M, Yusa S. Ectoplasmic specialization in the Sertoli cell: new vistas based on genetic defects and testicular toxicology. Anat Sci Int. 2003;78:1-16.

18. Weber JE, Russell D, Wong V, Peterson RN. Three-dimensional reconstruction of a rat stage V Sertoli cell. II. Morphometry of Sertoli-Sertoli and Sertoli-germ cell relationships. Am J Anat. 1983;167:163-179.

19. Schuppe HC, Meinhard A. Immune privilege and inflammation of the testis. Chem Immunol Allergy. 2005;88:1-14.

20. Russell LD. Movement of spermatocytes from the basal to the adluminal compartment of the rat testis. Am J Anat. 1977;148:313-328.
21. Romrell KJ, Ross MH. Characterization of Sertoli cell-germ cell junctional specializations in dissociated testicular cells. Anat Rec. 1979;193:23-41.

22. Aoki A, Fawcett DW. Impermeability of sertoli cell junctions to prolonged exposure to peroxidase. Andrologia. 1975;7: 63-76.

23. Jin Y, Penning TM. Steroid 5alpha-reductases and 3alphahydroxysteroid dehydrogenases: key enzymes in androgen metabolism. Best Pract Res Clin Endocrinol Metabol. 2001; 15:79-94.

24. Viger RS, Robaire B. Steady state steroid 5 alpha-reductase messenger ribonucleic acid levels and immunocytochemical localization of the type 1 protein in the rat testis during postnatal development. Endocrinology. 1995; 136:5409-5415.

25. Viger RS, Robaire B. The mRNAs for the steroid $5 \alpha$ -reductase izoenzymes, types 1 and 2, are differentially regulated in the rat epididymis. J Androl. 1996;17:27-34 .

26. Normington K, Russell DW. Tissue distribution and kinetic characteristics of rat steroid 5alpha-reductase isozymes. Evidence for distinct physiological functions. J Biol Chem. 1992;267:19548-19554.

27. Pratis K, O’Donnell L, Ooi GT, McLachlan RI, Robertson DM. Enzyme assay for 5alphareductase type 2 activity in the presence of 5alpha-reductase type 1 activity in rat testis. J Steroid Biochem Mol Biol. 2000;75:75-82.

28. Reyes EM, Camacho-Arroyo I, Nava G, Ceron MA. Differential methylation in steroid 5 alpha-reductase isozyme genes in epididymis, testis, and liver of the adult rat. J Androl. 1997;18:372-377.

29. Thigpen AE, Silver RI, Guileyardo JM, Casey M.L, McConnell JD, Russell DW. Tissue distribution and ontogeny of steroid 5 alpha-reductase isozyme expression. J Clin Invest.1993;92:903-910.

30. Robaire B, Henderson NA. Actions of 5alpha-reductase inhibitors on the epididymis. Mol Cell Endocrinol. 2006; 250:190-195.

31. Trybek G, Kolasa A, Marchlewicz M, Wenda-Różewicka L, Wiszniewska B. Immunolocalization of androgen receptor in the epididymis of rats with dihydrotestosterone deficiency. Reprod Biol. 2005;5:291-301.

32. Kolasa A. Epididymis in an experimental model of DHT deficiency: immunolocalization of ERalpha and ERbeta in rat epididymal epithelial cells. In vivo and in vitro studies. Ann Acad Med Stetin. 2006;52:13-21.

33. Kolasa A, Marchlewicz M, Adler G, Ciechanowicz A, Głabowski W, Wiszniewska B. Expression of E-SOD, GPX5 mRNAs and immunoexpression of $\mathrm{Cu} / \mathrm{ZnSOD}$ in epididymal epithelial cells of finasteride-treated rats. Andrologia. 2008;40:303-311.

34. Kolasa A, Marchlewicz M, Kurzawa R et al. The expression of inducible nitric oxide synthase (iNOS) in the testis and epididymis of rats with dihydrotestosterone (DHT) deficiency. Cell Mol Biol Lett. 2009;14:511-527.

35. Kolasa A, Marchlewicz M, Wenda-Rozewicka L, Wiszniewska, B. Morphology of the testis and the epididymis in rats with dihydrotestosterone (DHT) deficiency. Rocz Akad Med Bialymst. 2004;49:117-119.

36. Totty BA. Mucins. In: Bancroft JD, Gamble M, ed. Theory and practice of histological techniques. London, Churchill Livingstone; 2002:163-200.

37. Lie PP, Cheng CY, Mruk DD. Coordinating cellular events during spermatogenesis: a biochemical model. Trends Biochem Sci. 2009;34:366-373. 
38. Cheng CZ, Wong EWP, Yan HHN, Mruk DD. Regulation of spermatogenesis in the microenvironment of the seminiferous epithelium: New insights and advances. Mol Cell Endocrinol. 2010;315:49-56.

39. Eddy EM, Kahri AI. Cell association and surface features in cultures of juvenile rat seminiferous tubules. Anat Rec. 1976;185:333-358.

40. Kaya M, Harrison RG. The ultrastructural relationships between Sertoli cells and spermatogenic cells in the rat. Anat Rec. 1976;121:279-290.

41. Russell LD. Observations on rat Sertoli ectoplasmic ("Junctional") specializations in their association with germ cell of the rats testis. Tissue Cell. 1977;9:475-498.

42. Russell LD. Sertoli-germ cell interaction: a review. Gamete Res. 1980;3:179-202.

43. Cameron DF, Muffly KE. Hormonal regulation of spermatid binding. J Cell Sci. 1991;100:623-633.

44. O’Donnell L, Pratis K, Stanton PG, Robertson DM, McLachlan RI. Testosterone-dependent restoration of spermatogenesis in adult rats in impaired by $5 \alpha$-reductase inhibitor. J Androl. 1999;20:109-117.

45. O'Donnell L, McLachlan RI, Wreford NG, Robertson DM. Testosterone promotes the conversion of round spermatids between stages VII and VIII of the rat spermatogenic cycle. Endocrinology. 1994;135:2608-2614.
46. O'Donnell L, Stanton PG, Wreford NG, Robertson DM, McLachlan RI. Inhibition of 5 alphareductase activity impairs the testosterone-dependent restoration of spermiogenesis in adult rats. Endocrinology. 1996;137:2703-2710.

47. McLachlan RI, Wreford NG, Meachem SJ, De Kretser DM, Robertson DM. Effects of testosterone on spermatogenic cell populations in the adult rat. Biol Reprod. 1994; 51:945-955.

48. O'Donnell L, Stanton PG, Bartels JR, Robertson DM. Sertoli cell ectoplasmic specializations in the seminiferous epithelium of the testosterone-suppressed adult rat. Biol Reprod. 2000;63:99-108.

49. O'Donnell L, McLachlan RI, Wreford NG, de Kretser DM, Robertson DM. Testosterone withdrawal promotes the stage-specific detachment of round spermatids from the rat seminiferous epithelium. Biol Reprod. 1996;55: 895-901.

50. Lee JH, Choi KW, Lee SJ, Gye MC. Expression of beta-catenin in human testes with spermatogenic defects. Arch Androl. 2005;51:271-276.

51. Lee NPY, Cheng Y. Regulation of Sertoli cell tight junction dynamics in the rat testis via the nitric oxide synthase/ /soluble guanylate cyclase/cGMP/protein kinase G signaling pathway: an in vitro study. Endocrinology. 2003; 144:3114-3129.

Submitted: 23 June, 2010

Accepted after reviews: 30 January, 2011 